\title{
Performance Management System - A Noble Approach for Performance Enhancement of an Organisation
}

\author{
Ujjwal Kumar Ghatak \\ Ph.D Scholar, Rayalaseema University, Kurnool (A.P.), India
}

\begin{abstract}
Performance Management refers to a comprehensive scientific approach to ensure a link between efforts to individual employees with vision and goals of the organization, to achieve excellence in organization on one side and satisfaction and growth of employees on the other side. Therefore the performance management system is an important instrument to facilitate organization to accomplish its goal. Both Individual skills and contributions and organizational objective measurement is needed to develop the important element of the organization, which is human capital. Employees are the critical factor in performance management system, where glowing designed model of system will result strong management guarantee and better employees' performance which show the way to organization's success. With to proper use, performance management system will amazingly beneficial to an organization to enhance its performance, particularly in the management practices in Public Sector Unit(PSU) organization. Based on the emergent framework and extant research, suggessions have been projected which could enhance the efficacy of PMS processes of any organizations
\end{abstract}

Keywords: Performance management system (PMS), Maharatna Companies,Public sector Unit (PSU)

\section{Introduction}

Ask any manager in the modern times what he considers as the primary assets of his / her organization, the answer will be "People". We must recognize that the tacit dimensions of knowledge in an individual may be as vital to achieving organization goals as are the explicit, codified forms of knowledge that have been built up over the time. Today's manager is faced with a problem of increased magnitude how best to utilize the resources available in the organization and it is well established now that the human element is the largest single controllable variable. This suggests that if an organization has to maintain or improve its overall performance, it must improve the performance of the individuals within the organization. Hence it is of utmost importance that for managing and improving individual performance organizations must nurture:

- The ability to identify the variables that affect performance

- The ability to predict the changes that will result if variables are changed

- The ability to change the variables

- The ability to repeat or duplicate the changes.

There is so much dynamism in the business environment that the capacity to adapt and to shift our thinking is critical. The challenge is to transform institutions that have been hand wired for consistency, control and predictability into culture where learning, surprise and discovery are truly valued.

\subsection{Definition of Performance Management System}

Performance management system is the process of creating a work environment or setting in which people are enabled to perform to the best of their abilities. Performance management system begins when a job is defined as needed and ends only when the employee leaves the organization. It is a Continuous Process of

- Identifying

- Measuring

- Developing

The performance of individuals and teams

So, Performance Management System is, "a continuous process of identifying, measuring and developing the performance of individuals and teams and aligning performance with the strategic goals of the organization."

\subsection{Importance of Performance Management System}

- Performance Management System includes the following actions.

- Develop clear job descriptions.

- Select appropriate people with an appropriate selection process.

- Negotiate requirements and accomplishments in terms of performance standards, outcomes, and measures.

- Provide effective orientation, education, and training.

- Provide ongoing coaching and feedback.

- Design effective compensation and recognition systems that reward people for their contributions.

- Provide promotional/career development opportunities for staff.

- Assist with exit interviews to understand why valued employees leave the organization.

Improvement in performance can come from two sources: (1) technological changes such as higher investment per worker in capital goods and technological improvements in capital goods or (2) changing human behavior in 


\section{International Journal of Science and Research (IJSR) \\ ISSN (Online): 2319-7064}

Index Copernicus Value (2015): 78.96 | Impact Factor (2015): 6.391

organizations. Whereas increased mechanization technological change, and increased investment per worker in capital goods can all contribute to improved productivity, it is changes in human behavior which result in higher payoffs.

\section{Performance Management System - Conceptual Framework}

Performance Management is a process of designing and executing motivational strategies, interventions and drivers with an objective to transform the raw potential of human resource into performance. All human beings possess potential within themselves in a few or more functional areas. However, utilization and conversion of this potential into deliverable performance is often suboptimal due to a variety of reasons. Performance management acts as an agent in converting the potential into performance by removing the intermediate barriers as well as motivating and rejuvenating the human resource. Fig 1

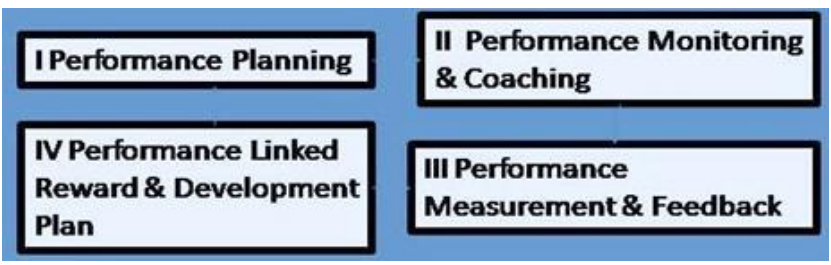

PMS Process Cycle

\subsection{Performance Planning}

Performance planning involves identifying the job areas and activities where the employee would like to put most of his efforts, do better than before and make its impact. Identifying Key performance areas and setting targets is a useful way of planning one's own performance. After identifying key performance areas, targets may be set under each key performance areas. Key Performance areas are the key or critical functions of a job role. Each job or Role makes its distinct contribution to the achievement of the organizational goal.

There are six steps to performance planning but the foremost step is performance planning session, a meeting between employee and manager.

- Identifying Job Performance activities; prior to the meeting, the employee and the manager should independently make a list of the employee's job performance activities.

- Developing a final list; the manager and employee now meet to review the two lists, they review each item and develop a final list of employees significant job activities.

- Determining priorities; Once and agreed final list has been developed, the employee and manager review each job activity to determine its importance.

- Developing performance expectations; the manager and employee now jointly develop specific performance process an outcome expectations. During the meeting the manager should try to determine if, the employee has a clear idea of the sequence of activities required to fulfill each of the expectations.
- Setting goals; by this time, both manager and employee should have some idea of the employee's development and growth needs. At this stage one or two job related development goals may be drawn for the employee.

- Setting check points; At this stage the employee and manager set specific times over the coming months when both can sit down to review performance. The purpose is not to evaluate but to identify problems and resolve them. The employee and the manager should met as and when necessary.

\subsection{Performance Standards}

Standards are vital to the success of any communication programme and a performance appraisal system certainly one of the most critical communication programmes in an organization. Standards are an integral part of Performance appraisal process. Performance appraisal standards provide both the rater and the ratee with a basis for describing work related progress in a manner that is mutually understandable. Performance standards provide a degree of uniformity in the non uniform world of work.

A specific performance standard should have certain characteristics.

- It should enable the user to differentiate between acceptable and unacceptable results.

- It should be of some challenge to the employee.

- It should be realistic and attainable.

- It should be a statement of the conditions that will exist and will assist in measuring a job responsibility.

- It should relate to or express a time frame for accomplishment.

- It should be observable and offer a means of measuring the performance against the requirements of the standards.

\subsection{Performance Goals}

Goals serve as bench marks or reference points against which performance on a measure can be compared. Goals are also important because they have a significant relationship with individual and group performance. The following are the requirement for meaningful goals:

- Goals should be challenging

- Goals should not only be demanding but also attainable.

- Goals that are perceived as too difficult or too easy lose their motivational value.

- Although participation will not guarantee performance improvement or attainment, yet there should be wide spread employee participation in setting goals. Such participation will result in greater acceptance of more difficult goals and in a higher commitment to goal attainment.

- Multiple goals should be set for each measure to establish a range within which performance on a given measure can be expected to vary. 


\section{International Journal of Science and Research (IJSR) \\ ISSN (Online): 2319-7064}

Index Copernicus Value (2015): 78.96 | Impact Factor (2015): 6.391

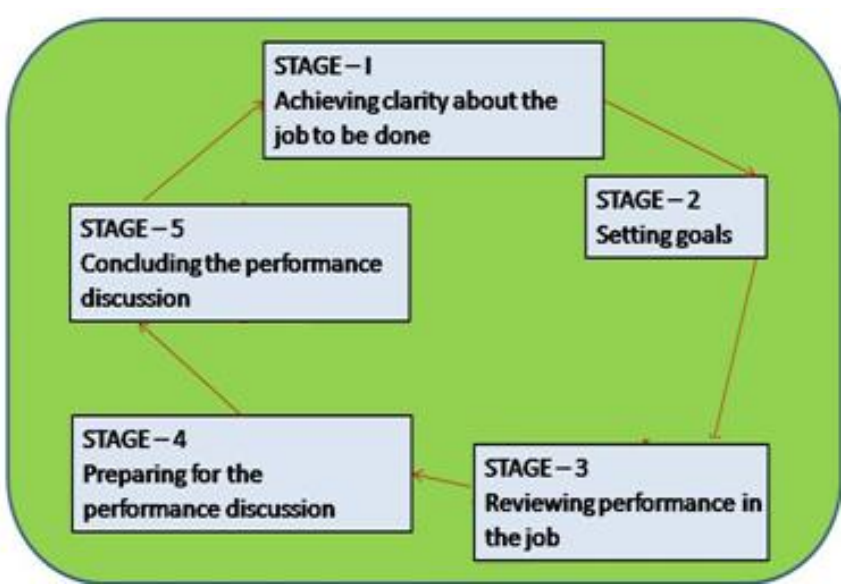

Figure 2: Goals Oriented PMS

\subsection{Reasons for Poor Performance:}

The job performance of executives in any organization depends on a number of variables such as the structure of the organization, human resource policies, technology, knowledge, skill and personality of executives etc. It is necessary to identify reasons of poor performances before starting any intervention of performance enhancement in the organization. An attempt was therefore made to analyze reasons of poor performance among executives. Following reasons were included:

1) Wrong/unscientific selection policies.
2) Performance appraisal system ineffective.

3) Career development opportunities not available.

4) Organizational structure bureaucratic and rigid.

5) No linkage between job performance and compensation and reward.

6) Role and responsibilities not well understood.

7) Executives lacking in knowledge and skill required for job.

8) Negative attitude of executives.

9) Highly repetitive nature of executive's job.

10) Dissatisfaction and frustration are common place.

\subsection{Performance Management Has the Following Characteristics}

a) Performance management is supposed to be owned and driven by line management and not by HR department or one or two executives.

b) There is emphasis on shared corporate goals and values.

c) Performance Management is not a package solution; it is something that has to be specific for a particular organization.

d) Executives of the organization should develop their own plan of managing performance of all employees.

There are following components of performance management:

1) Development of mission and goal statement of the company.

2) Development of business plan.

3) Communication goals and objectives to employees.

4) Defining role responsibilities.

5) Defining and measuring individual performance.

6) Developing appropriate reward and punishment strategies to modify behavior.

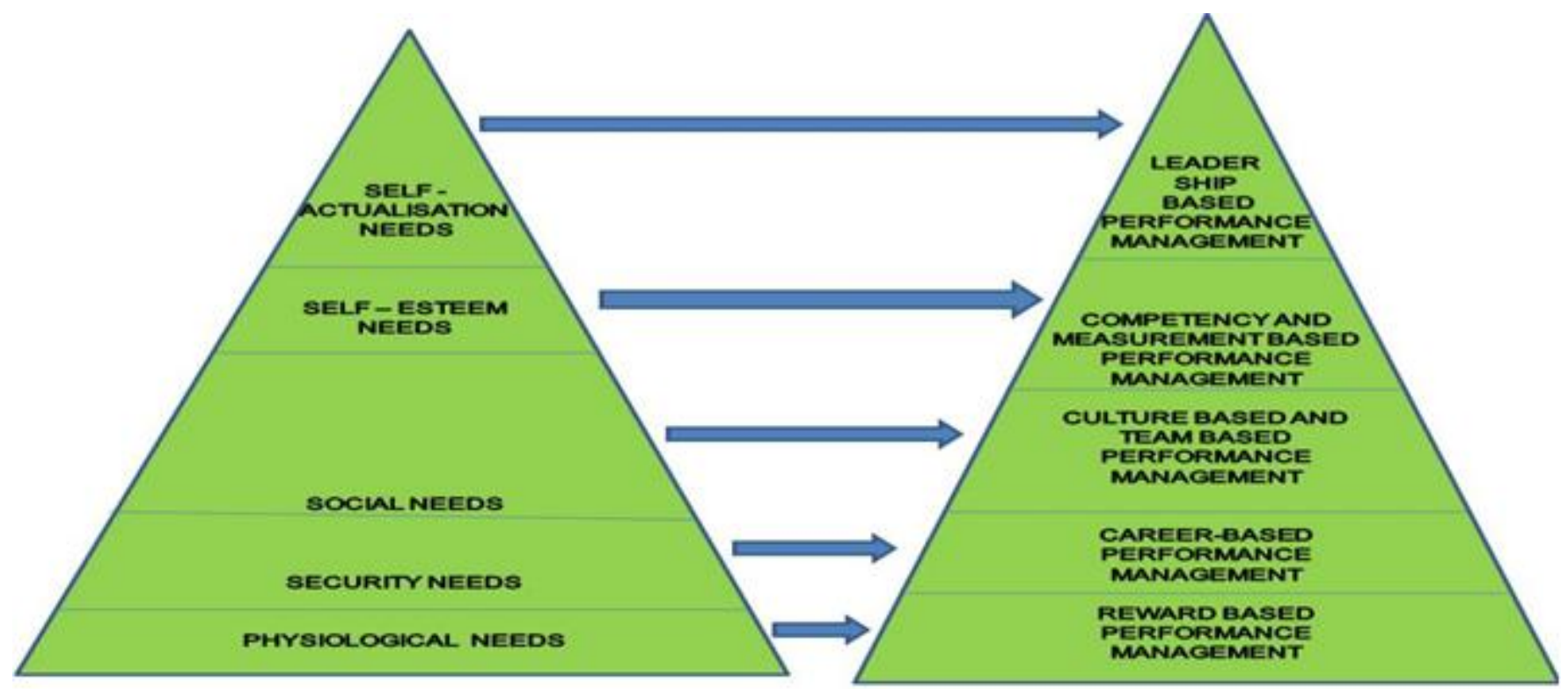

Figure 3: Maslow's Hierarchy of Needs Vs. Strategies of Performance Management

\section{Review of Literature}

An overview of the extensiv research related to performance management system is presented. Researcher tried to present a review of literature in a manner to exhibit how it enhance the perforance of organisation. Application of the concepts of performance management system as a way to achieve organizational success is addressed herewith from the significant works of Indian and overseas management specialists. 
3.1 A study on Performance Management System of Indian VIS-À-VIS International Companies: A Literature Review by Sandeep Kumar Joshi, Dy Manager-Human Resources, Shree Cement Ltd on 2016. This literature review examines the differences and similarities in the performance management system (PMS) in Indian and international companies. Performance management system is the transformation from performance appraisal system which is very important for every organization. In this study, it also investigates that what the important aspects are of PMS. The result indicates that most of the Indian and international companies did not have much differences in their PMS except cultural differences. The important aspect of PMS is its implementation in the organization and acceptance by the employees. By doing extensive literature review, it has been found that performance management system is not having much difference except cultural implication in both Indian and international companies. PMS has both negative and positive aspects in Indian and international companies. In most of the companies the traditional appraisal system is existing, where appraisal is done once or twice in a year and in some companies, feedback system was very poor or absent. This created bias in employee evaluation because if they have been given poor rating then they will not be in the position to know about their mistakes. If they are given good rating then they will not bother to know their mistakes so that they can improve. Moreover, companies introduced PMS but unable to implement properly which does not fulfill the purpose and some time employee acceptance level is low for the PMS. Therefore, introduction of PMS will not serve the purpose; it required effective implementation and well accepted by employees.

3.2 A study on Performance management system in Maharatna Companies (a leading public sector undertaking) of India - a case study of B.H.E.L., Bhopal (M.P.) by Rajesh K. Yadav, Nishant Dabhade, Department of Management, RKDF College of Engineering, Bhopal - 462047,Madhya Pradesh, on 2013. Extensive changes in the global economy have made it imperative for the governments all over the world to improve the quality of their governance structures. The Government of India has also introduced the New Public Management concepts in public administration with emphasis on 'results' or 'performance' to improve the efficiency and effectiveness of public services. This research aims to figure out the key variables that are having strong influence on Performance management system with special reference to BHEL, Bhopal (M.P.). Chi square test is applied in this paper to check the authenticity of data given by the respondents. We are also going to study the PM process, awareness level and satisfaction level of employees of BHEL and how the PM system affects the performance and career development of employees. It is suggested that changing culture requires leaders to understand the learning process dynamics and how the learning and unlearning of assumptions and beliefs can be manipulated to modify behavior. Hence cultural aspects could be one of the areas of training. An organization's leadership has the responsibility to develop a positive culture to facilitate the acceptance of performance appraisal among managers and their employees
3.3 A study on PERFORMANCE MANAGEMENT OF ACADEMIC STAFF AND ITS EFFECTIVENESS TO TEACHING AND RESEARCH - BASED ON THE EXAMPLE OF ESTONIAN UNIVERSITIES, by Kulno Türk at University of Tartu on 2016. The aim of the research is to identify options for developing performance management (PM) of the academic staff (AS) based on the example of Estonian universities (economics faculties). We want to find out more about PA and its interaction with other elements of performance - the effectiveness of teaching and research are studied. The analysis includes a review on how the PM system has developed over time, ascertaining special features with respect to the economic crisis. Methods included three questionnaire based surveys of AS carried out in 2013, interviews with nine academic leaders and seven focus group interviews were conducted. Qualitative methods involved the analysis of documentation universities, interviews and participatory observations within a case study. A detailed PA system enables the AS to achieve higher results specifically during periods of restructuring and change at universities, but causes a negative impact for quality and motivation of AS in times of crisis. During the stage of further development of the faculties, it would be necessary to pay more attention to qualitative indicators and reduce the number of quantitative indicators. It is necessary to develop the PM to be applied in conjunction with other management instruments (qualitative management, personnel management). AS emphasized the need for improvement in the quality of research and teaching even in conditions of scarce funding. As the motivation to engage in knowledge work is primarily intrinsic, the usage of detailed quantitative measures in PM should be handled with care. The impact of PA should not dominate teaching and research; it is also crucial to use other management instruments, for example strategic management and quality management.

3.4 A roadmap for developing, implementing and evaluating performance management systems by Elaine D. Pulakos, Ph.D on 2004. is executive vice president and director of the Washington, D.C. office of Personnel Decisions Research Institute (PDRI). Many factors will impact the effectiveness of an organization's performance management system, but three are most important. First, the system needs to be aligned with and support the organization's direction and critical success factors. Second, well-developed, efficiently administered tools and processes are needed to make the system user friendly and well received by organizational members. Third, and most important, is that both managers and employees must use the system in a manner that brings visible, value-added benefits in the areas of performance planning, performance development, feedback and achieving results. She said that to Make Sure the System must be Aligns with the culture and business needs of the organization. Matches the level of support for performance management that exists in the organization. Is considered an important tool for achieving business results by managers and employees. Is as user-friendly, straightforward and easy to use as possible.

3.5 A study on 'Performance Management' by Mr. Srinivas R Kandula, Director (Human Resource), Sasken Communication Technologies limited, Bangalore presented 


\section{International Journal of Science and Research (IJSR) \\ ISSN (Online): 2319-7064}

Index Copernicus Value (2015): 78.96 | Impact Factor (2015): 6.391

theory and practices of performance management in an integrated perspective. An attempt is made to present theory and practices of performance management in an integrated and pragmatic style. He stated about seven strategies, fourteen interventions and one hundred and forty drivers and all these cumulatively are expected to make an organization not only performance centric but also make performance management a fundamental system of organizational management.

3.6 A study on, Organizational performance management system: exploring the manufacturing sectors, by Dr. Chandan Kumar Sahoo, Associate Professor, School of Management, National Institute of Technology, Rourkela and Ms. Sambedna Jena, Research Scholar on 2012. This paper demonstrates the various practices of performance management system in the manufacturing sectors. The literature review of the popular performance management system utilized by the manufacturing sectors depicts that no single system is successful in improving the performance of a firm. The correct match between the firm and performance management system is essential for its success. The performance management system's function has a significant positive impact on performance of the employees when it's implemented successfully. The review also depicted certain issues on implementation of performance management system in the manufacturing units like costs, lack of strategic feedback system and incentive schemes which undermine the efficiency of a performance management system. Improvisation of performance is an ongoing process and the organization needs to strive to attain optimal level of value, so as to enhance the future potential business. Hence, the process of measuring the manufacturing performance management system needs frequent reviewing and monitoring to combat an increasingly competitive globalized business environment.

3.7 A study on 'Research on Human Resources Development: Present trends and Future Directions' by TV Rao, IIM, Ahmadabad reveals that HRD is a process by which the employees of an organization are helped in a continuous and planned way, to;

1) Acquire or sharpen capabilities required to perform various functions associated with their present or expected future roles;

2)Develop their general capabilities as individuals and discover and exploit their own inner potentials for their own and/or organizational development purposes; and

3)Develop an organizational culture in which supervisorsub-ordinate relationships, teamwork, and collaboration among sub-units are strong and contribute to the professional well-being motivation and pride of employees.

\section{Conclusion}

This paper clarifies the definition of Performance Management System with the help of extant research. It defines Performance Management System as a combination of four components: Performance planning, Performance monitoring \& Coaching, Performance Linked Reward and Development Plan and Performance Measurement and
Feedback system, organizational performance and competitive advantage. The overall rationale of this study was to test the key variables that are having brawny influence on Performance management system with special reference to Public Sectors. The researche has figured out the PM process, awareness level and satisfaction level of employees and how the PM system affects the performance and career development of employees. Although Performance management is more a philosophy than a set of policies and tools but the most prevalent notion of performance management is that of creating a shared vision of the purpose and aims of the organization, helping individual employees to understand and recognize their part in contributing to them and thereby managing and enhancing the performance of both individual and the organization.

\section{References}

[1] A roadmap for developing, implementing and evaluating performance management systems by Elaine D. Pulakos, Ph.D on 2004. is executive vice president and director of the Washington, D.C. office of Personnel Decisions Research Institute (PDRI)

[2] R. K. Sahu, "Performance management system", Excel publication, 2007, pp. 95-119.

[3] Sharmistha Bhattacharjee, Santoshi Sengupta, VSRDIJBMR 1(8) (2011) 496-513.

[4] Sahoo, Chandan K. and Jena, Sambedna. (2012). Organizational performance management system: exploring the manufacturing sectors. Industrial and Commercial Training, 44(5), 296 - 302.

[5] . Rajesh K. Yadav, Nishant Dabhade, Department of Management, RKDF College of Engineering, Bhopal, ” Performance management system in Maharatna Companies (a leading public sector undertaking) of India - a case study of B.H.E.L.,Bhopal (M.P.) International Letters of Social and Humanistic Sciences, 2013.

[6] Zulystiawati, Educational Management, Faculty of Education State University of Gorontalo, Indonesia, "Performance Management System: The Practices in the Public Organization in the Developing Countries" Information and Knowledge Management, Vol.3, No.4, 2014.

[7] Sandeep Kumar Joshi, “ Performance Management System of Indian VIS-À-VIS International Companies: A Literature Review", AT Journal of Exclusive Management Science - December 2014 -Vol 3 Issue 12 - ISSN 2277 - 5684.

[8] Kirti Sharda, “ Talent Management Systems in Indian Pharmaceutical Firms: Exploring an Emerging Typology", at Indian Institute Of Management Ahmedabad, W.P. No. 2016-03-52, March 2016.

[9] Performance Management Of Academic Staff And Its Effectiveness To Teaching And Research - Based On The Example Of Estonian Universities, by Kulno Türk at University of Tartu on 2016

[10] Text Book on 'Performance Management' by $\mathrm{Mr}$. Srinivas R Kandula, Director (Human Resource), Sasken Communication Technologies limited, Bangalore 